\title{
What is an Academic Journal? Problems Associated with the Transition to Electronic Publishing
}

\section{Beate Elvebakk}

\begin{abstract}
The article is based on interviews with the subject specialists employed at the University Library in Oslo in 2005, and describes the discussion surrounding the introduction of an "e-only" policy for academic journals, and the opposition it met, especially among the subject specialists from the humanities. It deals with the perceived problems in this early stage of the new publishing paradigm in the academe, and describes the worries of the librarians in the form of a set of stories about breakdowns, malfunctions and absences. The article concludes that although the electronic journal may seem not to have radically changed academic journals, a more inclusive approach to technology in use reveals that our ways of relating to the journals have changes significantly, and that we may not be aware of all the consequences that follow from this. Especially, this relates to how academic resources is being used, and consequences for the research that is being produced.
\end{abstract}

Keywords: Digital journals, Academic publishing, technological change

Evans (2008) issues a warning that electronic journals might be changing the very face of scholarship. He observes in his study that:

"As more journal issues came online, the articles referenced tended to be more recent, fewer journals and articles were cited, and more of the citations were to fewer journals and articles".

He links this development to user behaviour, conjecturing that rather than "browsing and perusing" users opt to do electronic literature searches and follow links, thus accessing an ever narrowing spectrum of journals and articles. This might seem as technological determinism in its crudest form, as he suggests that the digital technology does not only change how we use journals, but also what we read, and therefore ultimately how we think, and what we know.

While a causal link has certainly not been established, there is still reason to ask whether the transition to electronic publishing in the academic sphere has not been viewed too naively, when it has generally been discussed merely in terms of on the one hand control in terms of access, archiving, and finances (Bergstrom, 2001, Dewatripoint et al, 2007, Harnad, 1993, House of Commons 
Report, 2004, Liu, 2006, Odlyzko, 2000), and on the other, in terms of changes in journals' form, content, and style (Guedon, 1996, Macenzie Owen, 2005). As the number of journals has steadily increased, and their prices have risen steeply, especially up to the mid-nineties (King \& Tenopir, 2003), it has long been customary to speak of a "serial crisis" (Okerson, 1996) in the library sector. While it is important to focus on this crisis and on lingering concerns over archiving of electronic materials there might also be problematic aspects related to the features of the digital revolution in academic publishing perceived as being largely successful. While it is true that the overall picture is one of increased access to information, improved information retrieval and convenience for academic users, this is not the entire story. In this article, I will seek to supplement the existing discussion by highlighting some of the problems perceived and experienced by a group of university librarians from the humanities disciplines at the University of Oslo, in the period when digital journals were in the process of being introduced in their fields. I believe that the concerns of the librarians can serve not only to demonstrate how the access view of digitisation is based on an impoverished understanding of technology, but can also lend some credibility to developments like those reported by Evans, as being a likely outcome unless actively countered by users, instructors and librarians. The librarians, unlike the Library Board, were concerned with the actual needs and behaviours of users, and thus did not focus on access, but on consequences for present and future use of scholarly resources, and on the implications for the disciplines they were to represent. Also, they saw the new technology as changing relations between themselves and the library and library users, in ways that could eventually influence what resources were being used, and how they were used.

This article, then, seeks to use the librarians' experiences as a basis for saying something about how the transition to digital publishing may come to influence the relationship between academic readers (and thus writers) and their materials, and at the next turn, how this may influence scholarship in general. Such an approach may serve to complement the existing literature through showing that the notion of a successful transition to an electronic platform might be more problematic than it would first appear, and that power relations between publishers and academic communities do not merely extend to questions of prices and access to information.

Librarians were chosen as informants in this study in order to cover a group that is often neglected in studies that concentrate on the content rather than the format of publications. The focus is not so much on individual choices and behaviours as on the aggregated results which might not be visible to individual users.

\section{Background}

In 2004, the library board at the University of Oslo decided that whenever electronic versions of journals were available, subscriptions to paper journals should normally be cancelled. This policy was somewhat controversial among librarians within all disciplines, but nowhere was resistance as strong as among the subjects specialists from the humanities.

I will argue that the library board and the humanities librarians held somewhat 
different notions of what the digital journal was, what it encompassed, and hence, whether it was working well. The article is based on interviews with 47 librarians, subject specialists and administrative officers in the Oslo University Library carried out in 2005, at a time when the technology was still so recent that the informants were keenly aware of new problems and challenges.

In the early days of the internet, it was widely anticipated that the new technology would lead to important changes in the system of scholarly publishing, ranging from taking control back from the commercial publishers (Harrison, 1996) and thus providing a technical fix to the so-called "serial crisis" (Odlyszko, 2000), to changes in the form and practice of presenting scholarly results (Guedon, 1996). More recent reviews have concluded that the predicted revolution has not come about (Nentwick, 2003; Mackenzie Owen, 2005,), and expectations are on the whole more modest. So far, it seems that the traditional journals and traditional journal publishers have by and large retained their stronghold, and also, when it comes to the presentation of the articles, little but the medium has changed ${ }^{1}$.

For various reasons, most journals have chosen to retain their paper versions alongside the electronic ones, although academics increasingly make use of the electronic counterparts that are readily available at their desktops, rather than visiting the library, or retaining private subscriptions. At the time of my interviews, the transition to digital format was almost complete in most of the natural sciences and medicine, while the social sciences, and especially the humanities were seen to be "lagging behind", as many of their journals were still only available in paper form at the time the interviews were carried out ${ }^{2}$.

The task of the academic librarian is traditionally to make sure that highquality literature is being made available to the academic community, and that the relevant literature is being preserved for the use of present and future academics. At the University of Oslo, most of the disciplines have their own subject specialist, in charge of selecting relevant literature, through purchasing books and journal subscriptions. They should also provide guidance to those who wish to know more about available information resources, and give courses for students on how to locate and use information resources. The subject specialist usually has a background (typically a master's degree, but in several cases a doctorate) from a relevant discipline, so as to be able to make informed choices, and ascertain that the collection is at all times relevant and comprehensive, as far as possible within (often very considerable) budgetary constraints. Although faculty are encouraged to make suggestions as to what should be purchased, the responsibility for the collection lies firmly with the subject specialists, who are to make sure that faculty and staff have access to the literature they want or need, and that it also reflects what are perceived as central bodies of scholarship, and give the inexperienced user a fair impression of the state of the discipline.

Along with the technological development, the process of buying or subscribing to academic journals has also undergone major changes. Where the prevailing model used to be that journals were bought as individual titles, today they are usually bought in "bundles", ranging in size from a handful of journals to the entire portfolio of a major publisher. The contents of these bundles are typically fixed, meaning that 
libraries are as a rule not at liberty to add or subtract individual titles. The prices of these bundles can be negotiated, and for the larger bundles the negotiating institutions are frequently national or international library consortia, rather than individual libraries. Although these consortia have improved the libraries' negotiating power (Dewatripont et al., (2007) show that it is still limited, however), it is nevertheless the case that there exists widespread dissatisfaction about the prices publishers charge ${ }^{3}$. One consequence of this model was that a considerable share of the subject specialists' budgets was tied up ${ }^{4}$, meaning that they had very limited resources available for purchasing non-bundled journals and books 5 .

Changes have also taken place on the supplier side. The academic publishing houses have gone through numerous mergers and takeovers, and today, a few very big players dominate the field, with Elsevier the largest, controlling an alleged 20 percent of the world market (BNP Paribas, 2003). Journals published by scientific or scholarly societies have also frequently been bought by or their management outsourced to commercial companies, and there is an overall impression that the journal market has grown considerably more aggressive.

All of this means that the subject specialists' relationships with journals and publishing houses is very different from what it was twenty years ago. It was now very much seen as a matter of dealing with large commercial companies, who were furthering their own economic interests, and compared to whom the libraries had very limited influence.

\section{Trouble Stories}

At the time the interviews were carried out, many of the informants expressed keen interest in the research project, and indeed seemed to treat it as an opportunity to finally vent their grievances. The issues had obviously been discussed at length among them, but, given the complexity of the situation, and the multitude of problems and issues involved, there was no one place where the situation could be considered in its totality. The interviews thus provided a space where unrelated and unsystematic concerns could be raised, and were their complaints and reasons for resistance could finally be voiced.

Many expressed concern that the Library Board's enforced policy of cancellation of paper journals did not reflect the way the situation was experienced "on the floor", or in the library, as it were. One way to understand this conflict between the library management and the librarians, is to see it as a disagreement as to whether the electronic journals do in fact work. Obviously, the library management held that they did, and thus it should be uncontroversial to replace the paper journals, as the electronic ones can do the same job, and even better, as they are more convenient, searchable, take up less storage space, etc. We might recognise in this attitude the infamous "technology as neutral" approach (Wyatt, 1998).

The librarians, however, offered a number of examples of how the electronic journals failed to work, including their conceptions of the journal- not merely the technical hard- and software, but the entire socio-technical configuration of which they were part of; the administrative system, the librarians, the users and their competence and practices, and even the future of the library as guarantee for a certain disciplinary stability and as a reliable witness of the past. Their complaints and misgivings formed around a set of interlinking topics, which 
I have chosen to present as narratives about threats and failures, absences and lacunas.

\section{The story of the journal that wasn't there} Some of the ways in which the journals were seen not to work were very straightforward: even though the quality of the journal services was generally seen to have improved markedly over the last few years, it was still frequently the case that one would simply not be able to access the relevant articles. One of the librarians had checked this systematically, and found through a number of trials that for his portfolio, access to articles was denied in about $20 \%$ of attempts.

A further complication was that the electronic journal is not merely the bits that are being transferred- or not-to your computer, but that for any given library, it also consist in a sizeable supporting network, including journal publishers, journal agents, local technical and administrative staff, local and distant hardware and software, and all the relations between them. If some of the actors fail, or communication between them breaks down, the journal will not work. This meant, for instance, that many journals would typically fail to work in January, because somewhere along the line, the library's intention to continue or start a subscription had not been communicated, or someone had failed to act on this information, or a new technical set-up was not in place, or did not communicate with the old one, or the network had not been configured correctly. Even when such a mistake had been discovered, it would usually take a considerable amount of time to identify the source of the failure, and even longer to correct it. From the point of view of the subject specialists, technical errors were usually indistinguishable from administrative errors, as the end result would in either case be a journal that did not work, or simply was not there to be used.

There were also problems that were characterised by the subject specialists as "purely" technical in character, even if they often had an economic aspect. For instance, some journals would require different types of signs or symbols (such as Japanese signs or Russian letters), and these would in their turn depend on the software installed on the local computers. As some of these programmes took a lot of storage space, they could not be installed on the existing machine park. Consequently, Japanese signs, for instance, were only available on two of the library's computers. Complaints about such "technical" matters, however, would always migrate into other realms: should the library invest in bigger computers? Should the IT-people spend their time installing the relevant software? Should the students be expected to bring their own laptops to the library (as had been suggested by the library board)-and is it acceptable to suppose that they can all afford one? Should one expect students to read articles on the screen (also assumed by the Board)-and if not, is it fair that they are allotted only a quota of 100 pages of free print-outs each term, if higher education is in principle supposed to be free?

\section{The Story of the Fallible User}

In the interviews, it became clear that the subject specialists voiced their concern from a particular angle; they seemed to see themselves as spokespersons and representatives of the users, and, more indirectly, their disciplines-the "subjects" on which they were specialists, but of whom they were also, frequently, fervent defenders. 
When it came to users, the new policy seemed to assume that they preferred the electronic versions to paper journals, or that they were indifferent. The library staff, however, maintained that many users encountered problems in the new environment. For one thing, they argued that many users simply would not use journals if they were only available in electronic form. Access to electronic holdings may be a convenient solution for those who are familiar with the systems, but to inexperienced users the interfaces can appear confusing or opaque. User interfaces were not standardised, searches could be complicated, and finding the actual article frequently required many "clicks", so it was assumed that users might be lost on the way. The use of electronic resources requires skill that are perhaps not clearly visible to those who already possess them, and these skills are not purely technical, but also have to do with familiarity with the logic of database searches, experimenting with search parameters and so forth.

The librarians drew attention to two groups of users they considered to be challenged by the new system-older users and students. For the first group, the problem was linked on the one hand to established information seeking habits, and, on the other, to the level of technical competence. Even in the natural sciences, where use of electronic resources was clearly established as the norm, older academics were reported to favour paper journals, especially when it came to browsing recent issues, as many of them had for years routinely come to the library for their periodical updates, and found this habit hard to break. Many subject specialists in the natural sciences had therefore opted for a solution where the journals that were considered most central (typically journals like Science or
Nature) were retained in paper form in addition to the electronic subscriptions.

The group for whom the librarians most frequently expressed concern, however, were the students. They assumed that university faculty had already made some fundamental choices where their information seeking behaviours were concerned; that while they might browse or search a wide range of journals for information, there would also be a limited number of journals (typically estimated to be one to five) that they attended to in a different manner, as defining of their field or their speciality. The students, although often very familiar with digital media, were not seen to be competent users of academic resources in this manner. They were frequently found to be relying too heavily on general search engines, or resorted to Wikipedia, for instance, which raised concerns about the quality of the academic information they made use of.

A related problem was that even when the students made use of "proper" academic materials, such as journals or journal databases, the librarians feared that they did not know the field well enough to distinguish between good and mediocre, or relevant and irrelevant. There was general agreement that bachelor students used academic journals only to a very limited degree, and that master students tended to use them in a manner that differed from "the normal academic": they were seen to opt for specific thematic searches, rather than using journals as the organising object. This was one reason for worries about the transfer of purchasing decisions away from individual, academically qualified librarians, to commercial publishers. Librarians had been trained to signal the importance of books and journals through prominence of display, which, of course, is a practice that does not 
translate well to a database, especially not one that is bought "off the shelf".

The librarians thus saw users as being at risk in the new system. They suspected that they would settle for the first few hits in the database, rather than carry out the extensive searches necessary in order to find the best information, in other words that the searches could be described not as planned, but highly situated actions (Suchman, 1987). This concern especially related to novice users, but, given the context of academic research, was not restricted to them. One of the librarians reported how she had assisted a PhD candidate in locating relevant literature for his trial lecture, and had found that although the topic was French history, the articles they had been able to identify using databases were predominantly from English language journals. Although she did not know what literature the candidate had eventually made use of, the experience had made her aware that when working under time constraints, as is the case for trial lectures (but, she observed, also for most academic work in general), there was good reason to avoid literature from other linguistic groups or indeed from outside the full-text databases, as locating and gaining access would be a much more cumbersome process.

Now, what is reported above are perceptions about user groups, and they were mostly not supported by data. The librarians all spent a few hours every week working in the library help-desk, and along with interaction with their departments, this served as basis for their impressions. They also had access to user statistics from the publishers, but these were not considered to be very informative, as it was impossible to tell whether articles had been accessed or used. Several of the librarians also pointed out that they could not, in principle, give the kind of information needed: they could not tell whether the users had found the information they were looking for, whether they had spent a long time looking for it, and, as one librarian pointed out "they do not show the non-users".

\section{The Story of Small Cultures and Big Publishing Houses}

The users, then, were seen as small and relatively helpless when confronted with articles in the context of a large technological system, controlled by evergrowing commercial publishing houses (BNP Paribas, 2003) with aggressive pricing policies. On the other hand, the librarians also frequently referred to the library, the university, and even the country as small players in the technoeconomic system of journal publishing. They found their negotiating power to be very limited, and some also suspected that they were not prioritized by the publishing houses, so that malfunctions, for instance, might take longer to correct than would be the case for bigger universities.

The story of the $\mathrm{PhD}$ candidate in French history related above also draws attention to another aspect of the digitization process: The majority of academic journals owned by big publishing houses are English language publications, and these were also the first journals to be digitized. In digital full-text databases, the available literature is still overwhelmingly in English and journals from other language groups are severely underrepresented (UKScholarly Journals: A Baseline Report, 2006). This tendency was so pronounced that even journals from other major language groups, such as French, German or Spanish, were usually only available in paper form. 
While initiatives such as JSTOR had made vast amounts of historical materials available for researchers, only a very small minority of the journals available were in other languages than English, and this was even more pronounced for current editions.

The technological system then, in its current form, was not "neutral" with respect to language groups and cultures. In making most of the English language journals easily accessible ${ }^{6}$, it also rendered journals from other language groups comparatively difficult to access. Through increasing the visibility of some journals, the system reduced the visibility of others. Combined with the situatedness of users, this did not bode well for foreign-language journals. So another aspect of the distrust of big publishing houses was that they were seen to reinforce hegemonic academic cultures. The journals that had been made available early on were typically from the Anglo-American cultural tradition, and this was perceived as also being a threat to smaller publishing houses, language groups and academic traditions. If users made a habit of relating to electronic databases rather than the paper holdings, they would end up relating almost entirely to the Anglo-American traditions. This was also sometimes seen as being a problem with the bundling in the first place, because, as one of the informants put it "the bundles contain a lot of stuff that is relatively uninteresting, because they are American and contain many local American journals for which there has been no demand". But, of course, the idea behind the bundling is that this demand will be created.

One of the librarians interviewed considered this problem to go well beyond the question of academic language; to him (who himself had his background from a different culture), this also implied that when studying a given country or region, the theories and frameworks available to students and researchers had originated in the Anglo-American cultural sphere. The interpretations of events, then, risked being those of the hegemonic culture, rather than those of the culture being described. If, as seems likely, the present state of academic libraries encourages academics to increasingly migrate to electronic literature, it also leads them to ignore minority perspectives, local academic cultures, and alternative stories. Though it might be the case that this will change in time, it is nevertheless true that in this transitional period, user habits are being formed, especially among students, who are not well acquainted with the international literature ${ }^{7}$. The minor and transitional problems of lagging behind, from his perspective, blends into, or turns into, a major political and cultural battle.

\section{The Story of the Unstable Archive}

A paper journal, in spite of its limitations as an information carrier also has some obvious advantages. The upside of its inflexibility is its inflexibility-once it is there, it stays the same for a considerable period of time (provided, of course, that it is not lost or damaged ${ }^{8}$. The most obvious consequence of digitization was that the journals were no longer physical objects contained in the library building, but, as we have seen, somewhat transient parts of a large socio-technical system.

But the academic journal has always in fact been a socio-technical network. It has been upheld not only by editors and academics, but by printing presses and postal services, and of librarians and libraries with their complex filing and archiving systems. Obviously, the paper journals were not free-standing objects, but kept in place by a complex 
set of relations (Law \& Singleton, 2000), and these relations were well entrenched, and the configuration was stable and well understood. In the new system, as we have seen, many of the functions and relations were black-boxed (Latour \& Woolgar, 1986), and invisible to the librarians. Since the paper journals were part of a stable system, the librarians knew what to expect from them, and, as a general rule, this was also what they received. Unfortunately, this was not always the case for electronic journals. It was frequently mentioned that electronic journals were untrustworthy, in principle and in practice. As a matter of principle, the paper copy was seen as a guarantee that information would not undergo changes. History simply could not be rewritten when the library owned its own paper copies, and the librarians were concerned that a centrally located database on the premises of the publishing houses did not offer the same security ${ }^{9}$.

In practice there were worries that the digital journals were not, in actual fact, the same as the paper versions they were to replace. Sometimes, it was said, parts of the journals had been missing. Dual-language journals had been known not to include non-English articles, or for some of the articles only abstracts were available. From the librarians' professional point of view, it was a problem that relevant background information for acquisitions, such as lists of books received, advertisements and book reviews had sometimes not been digitized.

In one sense, archiving practices were certainly under threat, as most of the publishers did not offer guaranteed future access to "free" subscriptions, i.e. titles that did not form part of the basis for calculating bundle prices. A large number of journals to which the library now had access, was therefore likely to disappear if deals were renegotiated or cancelled. These subscriptions had turned into a service, rather than a commodity. A few of the librarians also mentioned that they had earlier subscribed to journals that were supposed to be "eternal access", but had in fact disappeared as a consequence of mergers or bankruptcy.

Some of them also linked this concern to the very nature of their disciplines, which, they felt; the library board did not fully comprehend.

"Within the humanities, and to some degree social sciences, the text is the discipline, and therefore the texts are not outdated as quickly as in medicine or natural sciences. The historical aspect is much more central to the humanities and social sciences."

A text that is a service, then, seemed to undermine their very disciplinary identity. But their professional identity was also at risk: one of the tasks of the librarians was also to secure that archive holdings were complete and appropriate, and given the complexity and opacity of the current system, they found it very hard to determine whether they did actually fulfill this duty.

"Very few people have the necessary competence-technical, juridical and so on-to say anything about archival access, so a lot of opinions are being thrown about. We worry about technical breakdowns, bankruptcy, etc. “

Even if future access in some form was guaranteed, this might for instance be in the form of CD-ROMs, which could be impractical, limit access, and also raise 
issues of retransferring between different media in the future. The new system thus made their competence appear insufficient, or even obsolete, as it was difficult to tell whether they actually did have access to archives, and whether this access would be sufficient in the years to come.

\section{The Story the Helpless Victims of Big Socio-technical System}

As might already be clear, one of the main impressions I got from subject specialists was that many saw their situation relative to the journals as one where they had moved from being in charge of a manageable task, to a position of being small and powerless in an encounter with formidable adversaries and problems. This new "smallness" manifested itself in several ways.

\footnotetext{
"It is also difficult to have an overview of the subscription situation, as when we have duplicate subscriptions, and it is hard to know what we actually have access to- this is all unsatisfactory."
}

One indication of this was that many of the librarians were not able to tell how many electronic journals they had in their portfolio, as the bundles frequently made the distinction between disciplines harder to uphold, and extra subscriptions might be added or subtracted without the specialists' knowledge.

There were, as we have seen, plenty of instances and situations where problems arose, and the systems broke down. But even when everything was working perfectly, the systems could be confusing. As several informants complained, there are many steps from locating the reference to actually seeing (not to mention printing) the article. When people also have to juggle different databases (some with only older volumes, some with only recent ones, some full-text, some reference, some fulltext for some articles), different interfaces and different choices of suppliers of the individual articles (some of which may well be dead links, or not covering the period in question), the process might not be experienced as altogether smooth, at least not to the inexperienced user.

The electronic journal was not seen to be an intuitively self-explanatory system. Indeed a couple of librarians told me that many of their users were not aware that their access to the electronic resources was through the library, but believed that access was universal, therefore being up for surprises when they tried to access the same resources from other locations. The unbounded character of the journals thus also made the traditional boundaries of the library appear less clear. The library buildings no longer defined the limits of the library, and the distinctions between inside and outside were becoming blurred and contested. It had been the case for a very long time, of course, that books and articles were constantly sent between libraries, and that users were allowed to take out books or copies of article, so the library had always been characterized by flows, leakages and circulation. It had, as we have seen, been a network for a long time.

These days, however, the network character of the journal was all the more obvious, perhaps because of its tendency to breakdown, and the apparent inability (or unwillingness) of the various elements to conform. The hammer appears as part of an equipment world only as it breaks (Heidegger, 1993), or, as pointed out by Bijker (1993), the bare bones of a sociotechnical system can be unveiled when the system collapses. (Along these lines, Kennan and Cecez-Kecmanovic (2007) 
suggest that the Internet as a new actor in the journal network has contributed to opening up the black box of scholarly publishing). So the system's proneness to breakdown was probably part of the explanation why the heterogeneous network of the digital journal stood out in its blaringimperfection and undisciplined complexity at the time of the study. The apparent malfunctioning of the system was what opened up this Pandora's Box of social, economic, cultural and political issues, where you might previously only have seen an academic journal.

\section{Discussion: Configurations, spaces and absences}

While the Library Boards' conception of the digital journal was a narrow one, where it simply replaced paper-based journals and overcame some of limitations in the process, the librarians tended to include a number of seemingly external factors. The users imagined by the library management were rational users of information, who should be equally able to access a journal whether it was in paper or digital form. If anything, they might be seen to favour the digital journals, perhaps because of the advantages of direct desktop access and searchability. The user, it was implied, was looking for a specific piece of information, and whatever method rendered this process more convenient, and access more efficient, would probably be preferred.

The librarians and subject specialists in my study, however, could be said to entertain notions of users and of technologies that are familiar from the last few decades of technology studies. They argued that users were fallible, bounded and situated actors, who were likely to respond to and interact with the digital technologies in different ways than those predicted by the library board, and that this response would, in turn, affect the nature of the knowledge that they acquired and produced. Similarly, they held that the technology was not a completely neutral improvement on earlier storing devices, but that it came as part of a network, that its form systematically changed power relations; changed patterns of visibility and invisibility, and that absences as well as presences were likely to have implications for configurations of users and information. Their observations demonstrate how the outsides and insides of technology cannot easily be demarcated, and that our notions of wholes, absences and relations play a major role for the workings as well as the conceptions of a technology.

The stories told in this article may seem unfocused, disparate, conservative, or simply protectionist. However, there was one central issue that united them, and that rendered them something more than just the misgivings of a group unable to keep up with technological development: they all related to how the mediating room of the library-space had disintegrated as an organising arena of interaction between librarians, literature and library users ${ }^{10}$, and to the novel and confusing orders and configurations that had taken over from this well-known and well-arranged space. Where the librarians had been used to relating to a (in both senses of the word) disciplined space, their task was now to control flows of people and information that could not be contained within the library building. The central phenomena are no longer the individual journals or articles (which, in a sense, do not even exist as such) or the encounter between the individual library user and the individual text, but that flows of 
information and people run smoothly as intended, and are not obstructed.

This new spatial arrangement also repositions the individuals in the system. While the subject specialists had earlier been an obligatory point of passage (Callon, 1986) for journals entering the library, just as the library, in its turn had been an obligatory point of passage for readers and lenders, flows of information were now passing through the (physical and virtual) library outside of the librarians control, and frequently without notice.

Indeed, one striking feature of the stories was how not being there is frequently as important a factor as being there. It was the absence of the French and Spanish journals in the databases that worried the librarians. And it was the absence of the users from the systems that was a problem, just as their absence from the current measuring systems was.

As a vivid illustration of how things had changed, I was told that in 2005 that the publishing platform Springer Link announced some of its services were temporarily unavailable due to the damages caused by hurricane Katrina, whose geographical centre, as we know, was in the south-eastern parts of the United States. The actual library collection was then affected by the weather thousands of kilometres away, making the de-centred and distributed nature of the library, as well as the technology, strikingly visible.

In the field of library studies, it has now become a commonplace that the library and work of the academic librarian has been transformed, and this change has been accompanied by the introduction of new concepts such as the "service paradigm" (Moyo, 2004), the "learning-oriented library" (Schmidt,
2004), and so forth. The typical solution to the perceived chaos has been a new focus on the librarian as instructor-we might suggest that the idea behind this is that the structure that is perceived to be dissolved in the library holdings must be reconstructed within each individual library user. This was also a correcting measure mentioned by many of my informants; some of the discipline of the library could be restored if the individual users were disciplined to think and act correctly around the information resources. In this way, the librarians tried to reposition themselves as obligatory passage points-this time, however, not to the library but to the proper ways to go about information management.

\section{Concluding Remarks: What is an Academic Journal?}

In one of my first interviews, I talked to a subject specialist who had held her position for many decades, and was now about to retire. She told me that the first electronic versions of journals in her field had been introduced about six years previously, and, like many of her colleagues, she was wary of the new cancellation policy. Among the reasons that she presented for her scepticism were technical problems, user preferences, and unresolved issues related to archiving. I was, however, particularly struck by the following reason, which she presented almost as an afterthought:

"It is also difficult to explain to the students what a journal is, if they never actually see one".

At the time, I remember sympathising with her wish to retain the journal as 
an instructional object, and to give the students a sense of the reality of the academic journals, beyond the masses of articles available to them in databases. Still, the sentence also seemed in a fundamental way to be begging the question, for, given that journals were collectively in the process of going electronic, they were arguably also turning into different kinds of entities. One might therefore think that the very perception that this was a problem revealed that she was stuck in the old paradigm, where the electronic version of a journal was always just an impoverished representation of the "real" underlying paper journal. When I later returned to this interview, however, the sentence appeared to me in a somewhat different light. It seemed to me now also to embody a sense of nostalgia, for a time when a journal was a indeed a concrete and manageable object, whose existence was indisputable and which could, as a matter of fact, be explained to the students by presenting it to them. Showing the students a journal, in this kind of context, also meant demonstrating the librarian's competence and her mastery of the objects. Her remark then appeared to me almost like an insistence that after all, there was something there that might be understood, and that the traditional competence of the librarians was still relevant. As the traditional objectcharacter of the journals had weakened, the traditional ways of managing, or even conceptualising them seemed to be threatened, too.

As we pointed out in the beginning, several studies of electronic journals have concluded that the academic journal does not seem to undergo major changes when being transferred to digital media. It is still mainly a one-to-many communication medium, it does not as a rule incorporate multimedia and more experimental forms of writing, such as use of hypertext, and articles are usually not subject to alterations or updates after having been published. While this may in one sense be true, if journals are studied as autonomous objects, it is nevertheless the case that when we look at the journal in its context of use, the digital journal appears to be a different kind of object from the paper journal, and an object that is managed and used in different ways. Patterns of use, ways of reading, and, eventually, new knowledge, are likely to be transformed in this process, in ways we may not yet be completely able to understand. The individual article, and the individual journal, which the subject specialists had been trained to revere as objects, are no longer the most central organising principle.

Some of the developments observed, however, can perhaps suggest certain risks and possible pitfalls. It seems reasonable to assume that if the current systems are left to the most powerful actors, the margins of the academe (geographically, culturally and financially) will be increasingly marginalised, and the centres will take over more of the power over the communications process. Some of the traditional gatekeepers are weakened, as others are able to focus more power around them. This development is far from certain; it can be upset by new publishing trends, open access journals, grass-roots protests or technological change; but for the time being, it seems as though to some degree we have ceded locally disciplined spaces and controlled objects for global flows, without completely understanding the consequences. 


\section{Notes}

1 This is the overall picture, but there are clearly many exceptions to this rule. In some disciplines important journals are open access, and, in some cases, non-commercial. There also exists a host of multimedia online journals that experiment with form and content, and some of the traditional journals now also include new types of content, such as films, or include interactive features.

2 In 2005, the percentages of the portfolios available in electronic form (exclusively or) varied widely among disciplines at the University Library of Oslo. In the natural sciences, almost all the journals that were deemed to be "central" were available in electronic form, whereas the percentage in the humanities typically ranged between 10 and 50, but for some of the smaller languages, almost no journals were online. Some of the online journals were also only available through JSTOR, and their "moving wall" concept meant that the most recent volumes were not in the database.

3 There exist several different pricing models for bundles and for electronic subscriptions. One of the most widely used is that libraries are charged on the basis of their paper subscriptions prior to transition to electronic services. Some publishers also charge on the basis of the number of faculty or students in the relevant institution (which creates problems for small disciplines in large institutions), and some favor a "pay per use" model.

4 An added complication is that fluctuating currency rates render costs unpredictable.

5 The overall economic rationality of new cancellation policy could be questioned, as the price difference between "e-only" and retaining paper subscriptions along with electronic subscriptions was often negligible. In addition, e-only subscriptions incur a $20 \%$ VAT, which will frequently mean that the overall costs of these subscriptions surpass those of the combined package. There was however a precedent that this cost was borne by the central university budget, rather than paid over library budgets.

6 English language journals were uniformly reported to be the first to be digitized. Although this situation is gradually changing, a report from the Research Information Network (UK Scholarly Journals Baseline Report, 2006) confirms that this was still the case

7 The hegemony of the Englishlanguage academic culture was already pronounced, and had been continually strengthened, so that, for instance, many German journals had been cancelled due to lack of use, and German books were now frequently purchased only when translated to English. This constituted a marked break with the Norwegian academic tradition in many disciplines.

8 This happens quite frequently, and this fact served as an important part of the motivation for developing the electronic journal base JSTOR. (Schonfeld, 2003)

9 This concern was far from universal. Some of the librarians were convinced that a problem this far-reaching must be resolved sooner or later, on a higher level, and others mentioned the agreement between the publishing house Elsevier and the Konijnlijke Bibliotheek in the Netherlands (Steenbakkers, 2003) as a possible solution. 
10 Brown \& Swan (2007) report "a sharp fall over the past five years in the number of researchers who visit their institution's library regularly".

\section{References}

Bergstrom, T.C.: (2001) 'Free labor for costly journals?' Journal of Economic Perspectives, Fall 2001. http://www. econ.ucsb.edu/ tedb/Journals / jeprevised.pdf

Bijker, W. (1993): 'Do Not Despair: There is Life after Constructivism'. Science, Technology \& Human Values, 18 (1): 113-138.

BNP Paribas Report on Professional Publishing, (2003).

Brown, S. \& A. Swan (2007): Researchers' use of academic libraries and their services: a report commissioned by the Research Information Network and the Consortium of Research Libraries, Research Information Network.

Callon, M.: (1986), "Elements of a sociology of translation: Domestication of the Scallops and the Fishermen of St Brieuc Bay". In J. Law (Ed.), Power, Action and Belief: A New Sociology of Knowledge? (London, Routledge): 196233.

Dewatripont, et al (2006): Study on the economic and technical evolution of the scientific publications markets in Europe. Final Report, January 2006. http://ec.europa.eu/research/ science-society/pdf/scientificpublication-study_en.pdf

Evans, J.A. (2008): 'Electronic Publication and the Narrowing of Science and Scholarship'. Science 18 July 2008. 321 (5887): 395 - 399.

Guedon, J.C. (1996): 'Electronic Academic Journals: From Disciplines to 'Seminars'?' In TM Harrison \& T Stephen (eds.) (1996): Computer
Networking and Scholarly Communication in the Twenty-FirstCentury University. (Albany, NY: State University of New York Press): 335-350. Harnad, S. (1995): 'Universal FTP Archives for Esoteric Science and Scholarship: A Subversive Proposal.' in A. Okerson \& J. O’Donnell (eds), (1996): Scholarly Journals at the Crossroads; A Subversive Proposal for Electronic Publishing, (Washington, DC: Association of Research Libraries). Heidegger, M. (1993): Sein und Zeit. (Tübingen: Max Niemayer Verlag)

House of Commons Science and Technology Committee. Scientific Publications: Free for all? Select Committee on Science and Technology Tenth Report, (2003-2004). http:// www.publications.parliament. u k / pa / c m 200304 / c m select / cmsctech/399/39901.htm

Kennan, M.A. \& Cecez-Kecmanovic, D. (2007): 'Reassembling Scholarly Publishing: Institutional Repositories, Open Access, and the Process of Change'. Australian Conference on Information Systems: The 3 Rs: Research, Relevance and Rigour Coming of Age, December 5-7, 2007. Available at SSRN: http://ssrn.com/ abstract $=1030964$

King, D.W. \& Tenopir, C. (2003): 'Patterns of Journal Use through Three Evolutionary Phases'. D-Lib Magazine, vol. 9 , no. 5 .

Latour, B. \&Woolgar, S. (1986): Laboratory Life. The Construction of a Scientific Fact. (Princeton: Princeton University Press).

Law, J. \& Singleton, V. (2000): 'This is Not an Object', published by the Centre for Science Studies, Lancaster University, Lancaster LA1 4YN, UK, at http:// www.comp.lancs.ac.uk/sociology/ papers/Law-Singleton-This-is-Notan-Object.pdf 
Liu, L.G. (2006): 'Factors Determining Subscription Prices of Scholarly Journlas in Business Discipline: Themes and Variations'. Library Collections, Acquisitions, \& Technical Services 29: 382-394.

Mackenzie Owen, J.S. (2005): The scientific article in the age of digitization. (Amsterdam). http://dare. uva.nl/document/17843

Moyo, L.M. (2003): 'Electronic Libraries and the Emergence of New service Paradigms'. The Electronic Library. 22 (3): 220-230.

Nentwich, M (2003): Cyberscience. Research in the Age of the Internet. (Vienna: Austrain Academy of Sciences Press).

Odlyzko, AM (2000): 'The future of scientific communication', in P. Wouters and P. Schroeder, eds., Access to Publicly Financed Research: The Global Research Village III, (Amsterdam: NIWI), pp. 273-278

Okerson, A. (1996): 'University Libraries and Scholarly Communication'. In R.P. Peek, \& G.B. Newby, (eds.) (1996): Scholarly Publishing. The Electronic Frontier. (Cambridge, MA: MIT Press): 281-200.
Schonfeld, R.C. (2003): JSTOR. A History. (Princeton, NJ: Princeton University Press).

Steenbakkers, J.F. (2003): 'Permanent archiving of electronic publications'. Serials: The Journal for the Serials Community. 16 (1): 33-36.

Suchman, L. (1987): Plans and Situated Actions. The Problem of Human-Machine Communication. (Cambridge: Cambridge University Press).

UK Scholarly Journals: A Baseline Report (2006). Report Commissioned by the Research Information Network (RIN), Department of Trade and Industry (DTI), and Research Councils UK (RCUK). www.rin.ac.uk/files/Executive Summary.pdf

Wyatt, S. (1998): Technology's Arrow. Developing Information Networks for Public Administration in Britain and the United States. (Maastricht: Maastricht: Universitaire Pers)

Beate Elvebakk

Institute of Transport Economics

Gaustadalléen 21, 0349 Oslo

Norway

Beate.elvebakk@tik.uio.no 